\title{
Non contiguous-finished genome sequence and description of Microbacterium gorillae
} sp. nov.

\author{
Linda Hadjadj', Jaishriram Rathored', Mamadou Bhoye Keita', Caroline Michelle ${ }^{1}$, Anthony Levasseur' \\ Didier Raoult ${ }^{1,2}$, Pierre-Edouard Fournier ${ }^{1}$, Jean-Marc Rolain ${ }^{1}$ and Fadi Bittar ${ }^{1 *}$
}

\begin{abstract}
Strain G3 ${ }^{\top}$ (CSUR P207 = DSM 26203) was isolated from the fecal sample of a wild gorilla (Gorilla gorilla subsp gorilla) from Cameroon. It is a Gram-positive, facultative anaerobic short rod. This strain exhibits a $16 \mathrm{~S}$ rRNA sequence similarity of $98.2 \%$ with Microbacterium thalassium, the closest validly published Microbacterium species and member of the family Microbacteriaceae. Moreover, it shows a low MALDI-TOF-MS score (1.1 to 1.3) that does not allow any identification. Thus, it is likely that this strain represents a new species. Here we describe the phenotypic features of this organism, the complete genome sequence and annotation. The 3,692,770 bp long genome (one chromosome but no plasmid) contains 3,505 protein-coding and 61 RNA genes, including 4 rRNA genes. In addition, digital DNA-DNA hybridization values for the genome of the strain $\mathrm{G}^{\top}{ }^{\top}$ against the closest Microbacterium genomes range between 19.7 to 20.5, once again confirming its new status as a new species. On the basis of these polyphasic data, consisting of phenotypic and genomic analyses, we propose the creation of Microbacterium gorillae sp. nov. that contains the strain G3 ${ }^{T}$.
\end{abstract}

Keywords: Microbacterium gorillae, Genome, Culturomics, Taxonomo-genomics, Gorilla stool sample

\section{Introduction}

Strain G3 ${ }^{\mathrm{T}}$ (= CSUR P207 = DSM 26203) is the type strain of Microbacterium gorillae sp. nov. This bacterium is a Gram-positive, non-spore-forming, indole-negative, facultative anaerobic rod shaped bacillus. It was isolated from the feces of western lowland gorilla in Cameroon as part of a culturomics study to describe the bacterial communities of the gorilla gut [1]. By applying a large variety of culture conditions, culturomics allowed previously the isolation of numerous new bacterial species from gorilla fecal samples [1].

Furthermore, since the creation of the genus Microbacterium by Orla-Jensenin (1919) [2] to date, 91 bacterial species belonging to this genus have been validly published [3]. These species are Gram-positive and nonendospore-forming bacteria. Many studies have described

\footnotetext{
* Correspondence: fadi.bittar@univ-amu.fr

${ }^{1}$ Unité de recherche sur les maladies infectieuses et tropicales émergentes (URMITE), UM63, CNRS7278, IRD 198, Inserm 1095, IHU Méditerranée Infection, Faculté de Médecine et de Pharmacie, Aix-Marseille Université, Marseille, France

Full list of author information is available at the end of the article
}

Microbactertium species in diverse origins including human clinical specimens, soil, sea sediments, plants and hairspray [4-7].

In this report, we present a summary classification, phenotypic features for M. gorillae sp. nov. strain $\mathrm{G}^{\mathrm{T}}$, together with the description of the complete genome sequence and annotation. These characteristics support the circumscription of the species M. gorillae [8].

\section{Organism information Classification and features}

Information about the fecal sample collection and conservation are described previously [1]. Strain $\mathrm{G}^{\mathrm{T}}$ (Table 1) was isolated in January 2012 as part of a culturomics study [1] by cultivation on Columbia agar supplemented with sheep blood (BioMérieux, Craponne, France).

When compared to sequences available in GenBank, the $16 \mathrm{~S}$ rRNA gene sequence of M. gorillae strain G3 ${ }^{\mathrm{T}}$ (GenBank accession number JX650056) exhibited an identity of $98.2 \%$ with Microbacterium thalassium, the 
Table 1 Classification and general features of Microbacterium gorillae strain $\mathrm{G}^{\top}$

\begin{tabular}{|c|c|c|c|}
\hline MIGS ID & Property & Term & $\begin{array}{l}\text { Evidence } \\
\text { code }^{\mathrm{a}}\end{array}$ \\
\hline & \multirow[t]{8}{*}{ Classification } & Domain: Bacteria & TAS [34] \\
\hline & & Phylum: Actinobacteria & TAS [35] \\
\hline & & Class: Actinobacteria & TAS [35] \\
\hline & & Order: Actinomycetales & TAS [2] \\
\hline & & Family: Microbacteriaceae & TAS [36] \\
\hline & & Genus: Microbacterium & TAS [2] \\
\hline & & $\begin{array}{l}\text { Species: Microbacterium } \\
\text { gorillae }\end{array}$ & IDA \\
\hline & & Type strain: $G 3^{\top}$ & IDA \\
\hline & Gram stain & Positive & IDA \\
\hline & Cell shape & Rod-shaped & IDA \\
\hline & Motility & Non-motile & IDA \\
\hline & Sporulation & Non-sporulating & IDA \\
\hline & Temperature range & Mesophilic & IDA \\
\hline & $\begin{array}{l}\text { Optimum } \\
\text { temperature }\end{array}$ & $25^{\circ} \mathrm{C}$ & IDA \\
\hline & pH range; Optimum & Not determined & \\
\hline & Carbon source & Varied (see Additional file 4) & IDA \\
\hline MIGS-6 & Habitat & Gorilla gut & IDA \\
\hline MIGS-6.3 & Salinity & $2 \% \mathrm{NaCl}$ & IDA \\
\hline MIGS-22 & $\begin{array}{l}\text { Oxygen } \\
\text { requirement }\end{array}$ & Facultative anaerobic & IDA \\
\hline MIGS-15 & Biotic relationship & Free living & IDA \\
\hline \multirow[t]{3}{*}{ MIGS-14 } & Pathogenicity & Unknown & \\
\hline & Biosafety level & 2 & NAS \\
\hline & Isolation & Gorilla feces & IDA \\
\hline MIGS-4 & Geographic location & Cameroon & IDA \\
\hline MIGS-5 & $\begin{array}{l}\text { Sample collection } \\
\text { time }\end{array}$ & July 2011 & IDA \\
\hline MIGS-4.1 & Latitude & $2^{\circ} 47^{\prime} 2.1768^{\prime \prime}$ & IDA \\
\hline MIGS-4.2 & Longitude & $13^{\circ} 1^{\prime} 49.6986 "$ & IDA \\
\hline MIGS-4.4 & Altitude & $>600$ m above sea level & IDA \\
\hline
\end{tabular}

${ }^{a}$ Evidence codes - IDA: Inferred from Direct Assay; TAS: Traceable Author Statement

(i.e., a direct report exists in the literature); NAS: Non-traceable Author Statement (i.e., not directly observed for the living, isolated sample, but based on a generally accepted property for the species, or anecdotal evidence). These evidence codes are from the Gene Ontology project [37]. If the evidence is IDA, then the property was directly observed for a live isolate by one of the authors or an expert mentioned in the acknowledgements

closest validly published Microbacterium species. This value was equal to the percentage of $16 \mathrm{~S}$ rRNA gene sequence threshold recommended by Meier-Kolthoff et al. for class Actinobacteria to delineate a new species without carrying out DNA-DNA hybridization with maximum error probability of $0.1 \%$ [9]. Figure 1 presents the $16 \mathrm{~S}$ rRNA based tree for the strain $\mathrm{G}^{\mathrm{T}}$ and other Microbacterium species.
Different growth temperatures $\left(20,25,30,37,45^{\circ} \mathrm{C}\right)$ were tested. Growth occurred between $25^{\circ} \mathrm{C}$ and $37{ }^{\circ} \mathrm{C}$, but the optimal growth was observed at $25^{\circ} \mathrm{C}, 24 \mathrm{~h}$ after inoculation. No growth occurred at 20 and $45^{\circ} \mathrm{C}$. Colonies were $0.8 \mathrm{~mm}$ in diameter, appear as gray color on Columbia agar supplemented with sheep blood. Growth of the strain was tested under anaerobic and microaerophilic conditions using GENbag anaer and GENbag microaer systems, respectively (BioMérieux), and under aerobic conditions, with or without $5 \% \mathrm{CO}_{2}$. Growth was achieved under aerobic (with and without $\mathrm{CO}_{2}$ ), microaerophilic and anaerobic conditions. Gram staining showed Gram positive short bacilli (Fig. 2, left panel). A motility test with API M medium (BioMérieux) produced a negative result. Cells grown on agar do not sporulate and the rods have a mean length of $1 \mu \mathrm{m}$ and a mean width of $0.5 \mu \mathrm{m}$. Both the length and the diameter were determined by negative staining transmission electron microscopy (Fig. 2, right panel).

Strain $G 3^{\mathrm{T}}$ exhibited catalase activity but not oxidase activity using ID color catalase and oxidase reagent, respectively (BioMérieux). In assays with API $50 \mathrm{CH}$ system (BioMérieux), strain $\mathrm{G} 3^{\mathrm{T}}$ produced acid from esculin, D-cellobiose, D-maltose, D-lactose, D-mannose, Dmannitol, D-saccharose, D-trehalose and gentiobiose. By contrast, acid production was not observed for glycerol, erythritol, D-arabinose, L-arabinose, D-ribose, D-xylose, Lxylose, D-adonitol, methyl- $\alpha \mathrm{D}$-xylopyranoside, Dgalactose, D-glucose, L-fructose, L-sorbose, L-rhamnose, dulcitol, inositol, D-sorbitol, methyl- $\alpha \mathrm{D}$-mannopyranoside, Methyl- $\alpha \mathrm{D}$-glucopyranoside, xylitol, D-tagatose, Dturanose, D-lyxose, D-fucose, L-fucose, D-arabitol, Larabitol, potassium gluconate, potassium 2-cetogluconate, potassium 5-cetogluconate, D-melezitose, D-raffinose, Glycogen, $\mathrm{N}$-acetylglucosamin, amygdalin, arbutin, salicin and hydrolysis of starch. Using APIZYM, positive enzyme activities were observed for esterase (C4), esterase lipase (C8), leucine aramidase, phosphatase acid, naphtol-AS-BIphosphohydrolase, $\alpha$-mannosidase, $\alpha$ - glucosidase and $\mathrm{N}$-acetyl- $\beta$-glucosaminidase. Negative results for lipase (C14), phosphatase alcalin, valine arylamidase, cystine arylamidase, trypsin, $\alpha$-chymotrypsin, $\alpha$-galactosidase, $\beta$ - galactosidase, $\beta$-glucosidase, $\beta$-glucuronidase, $\beta$ glucosidase, and $\alpha$-fucosidase.

M. gorillae is susceptible to amoxicillin $(25 \mu \mathrm{g})$, erythromycin (15UI), doxycyclin (30UI), rifampicin $(30 \mu \mathrm{g})$, vancomycin $(50 \mu \mathrm{g})$, amoxicillin-clavulanic acid $(20 \mu \mathrm{g}+10 \mu \mathrm{g})$, trimethoprim-sulfamethoxazole $(1.25 \mu \mathrm{g} / 23.75 \mu \mathrm{g})$ and imipenem $(10 \mu \mathrm{g})$ but resistant to ciprofloxacin $(5 \mu \mathrm{g})$ and gentamycin $(15 \mu \mathrm{g})$.

When compared to other Microbacterium species [10-16], M. gorillae sp. nov. strain G3 ${ }^{\mathrm{T}}$ exhibited the phenotypic differences detailed in Additional file 1: Table S1. 


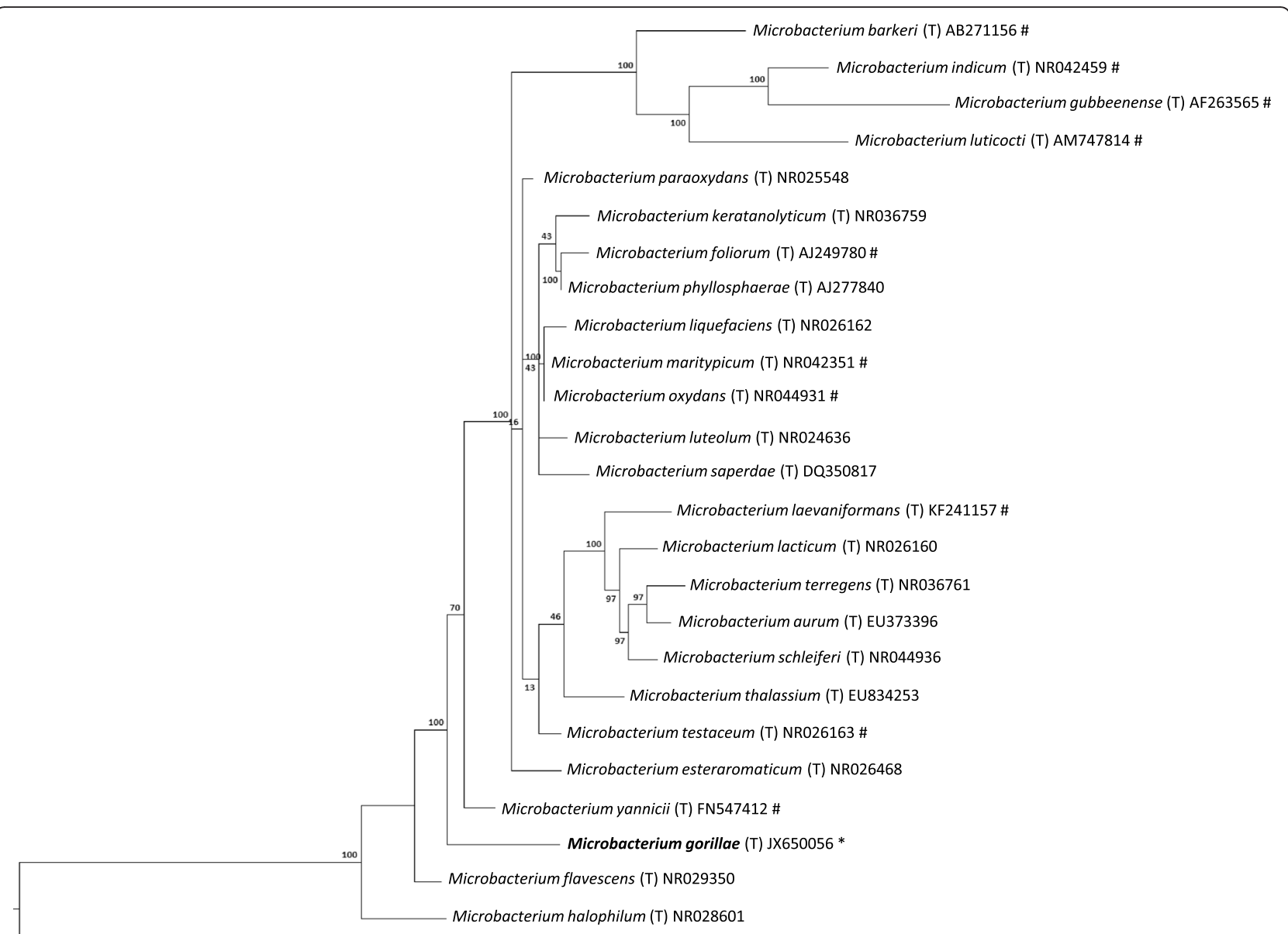

Corynebacterium diphtheriae (T) BX248360*

Fig. 1 Phylogenetic tree highlighting the position of Microbacterium gorillae strain G3 ${ }^{\top}$ relative to other type strains within the Microbacterium genus using $16 \mathrm{~S}$ rRNA gene. GenBank accession numbers are indicated in parentheses. Sequences were aligned using MUSCLE. Alignments were then cleaned from highly divergent blocks using Gblocks version 0.91b [38]. Maximum likelihood (ML) phylogenetic tree was generated using RAXML [39], employing the GTR GAMMA substitution model with 500 bootstraps. Numbers at the nodes are percentages of bootstrap values obtained by repeating the analysis 500 times to generate a majority consensus tree. Corynebacterium diphtheriae was used as outgroup. The scale bar represents a rate of substitution per nucleotide position of 0.02 . (T) indicates that the sequence used in the tree is from the type strain of the species.* indicates the strains used in the tree have a sequenced genome. \# indicates that a sequenced genome is available for this species but not for the strain used to build the tree

\section{Extended feature descriptions}

Matrix-assisted laser-desorption/ionization time-of-flight (MALDI-TOF) MS protein analysis was carried out as previously described [17] using a Microflex spectrometer (Bruker Daltonics, Leipzig, Germany). Twelve distinct deposits were done for strain $\mathrm{G} 3^{\mathrm{T}}$ from 12 isolated colonies. Two microliters of matrix solution (saturated solution of alpha-cyano-4-hydroxycinnamic acid) in $50 \%$ acetronitrile and $2.5 \%$ trifluoroacetic-acid were distributed on each smear and submitted at air drying for five minutes. Then, the spectra from the 12 different colonies were imported into the MALDI BioTyper software (version 2.0, Bruker) and analyzed by standard pattern matching (with default parameter settings) against 5,626 bacterial spectra including 43 spectra from 33 Microbacterium species, used as reference data, in the BioTyper database. Briefly, a score $\geq 2$ with a species with a validly published name provided allows the identification at the species level, a score $\geq 1.7$ but $<2$ allows the identification at the genus level; and a score $<1.7$ does not allow any identification. For strain $\mathrm{G}^{\mathrm{T}}$, no good score was obtained, suggesting that our isolate was not a member of any known species. We incremented our database with the spectrum from strain $\mathrm{G}^{\mathrm{T}}$ (Additional file 2: Figure $\mathrm{S} 1$ ). The gel view highlighted spectrum differences with other Microbacterium species (Additional file 3: Figure S2). 


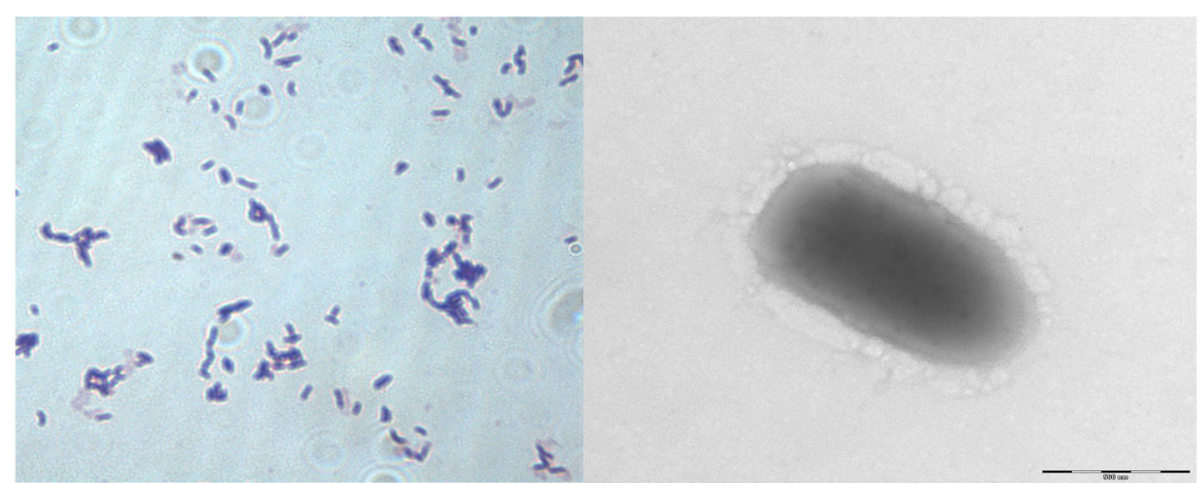

Fig. 2 Gram staining (left panel) and Transmission electron microscopy using a Morgani 268D (Philips) at an operating voltage of $60 \mathrm{kV}$ (right panel) of M. gorillae strain $\mathrm{G}^{\mathrm{T}}$. The scale bar represents $500 \mathrm{~nm}$

\section{Genome sequencing information Genome project history}

According to phenotypic characteristics of this strain and MALDI-TOF result and because of the low16S rRNA similarity to other members of the genus Microbacterium, it is likely that the strain represents a new species and thus it was chosen for genome sequencing. It was the $20^{\text {th }}$ genome of a Microbacterium species (Genomes Online Database) and the first genome of Microbacterium gorillae sp. nov. A summary of the project information is shown in Table 2. The GenBank accession number is CDAR00000000 and consists of 14 contigs. Table 2 shows the project information and its association with MIGS version 2.0 compliance [18].

\section{Growth conditions and genomic DNA preparation}

Microbacterium gorillae sp.nov strain $\mathrm{G}^{\mathrm{T}}$ (= CSUR P207 = DSM 26203) was grown aerobically on $5 \%$ sheep blood-enriched Columbia agar (BioMérieux) at $25{ }^{\circ} \mathrm{C}$.

Table 2 Project information

\begin{tabular}{lll}
\hline MIGS ID & Property & Term \\
\hline MIGS-31 & Finishing quality & High-quality draft \\
MIGS-28 & Libraries used & Mate pair and paired end \\
MIGS-29 & Sequencing platforms & MiSeq-Illumina \\
MIGS-31.2 & Fold coverage & 213X \\
MIGS-30 & Assemblers & Spades \\
MIGS-32 & Gene calling method & Prodigal \\
& Locus Tag & BN1193 \\
& GenBank ID & CDAR00000000 \\
& GenBank Date of Release & November 04, 2014 \\
& GOLD ID & Gp0025154 \\
& BIOPROJECT & PRJEB7582 \\
MIGS-13 & Source Material Identifier & G3 \\
& Project relevance & DSM 26203, CSUR P207 \\
\hline
\end{tabular}

Bacteria grown on four Petri dishes were resuspended in $3 \times 500 \mu \mathrm{l}$ of TE buffer and stored at $80{ }^{\circ} \mathrm{C}$. Then, $500 \mu \mathrm{l}$ of this suspension were thawed, centrifuged $3 \mathrm{~min}$ at $10,000 \mathrm{rpm}$ and resuspended in $3 \times 100 \mu \mathrm{L}$ of G2 buffer (EZ1 DNA Tissue kit, Qiagen). A first mechanical lysis was performed by glass powder on the Fastprep-24 device (Sample Preparation system, MP Biomedicals, USA) using $2 \times 20 \mathrm{~s}$ cycles. DNA was then treated with $2.5 \mu \mathrm{g} /$ $\mu \mathrm{L}$ lysozyme (30 min at $37{ }^{\circ} \mathrm{C}$ ) and extracted using the BioRobot EZ1 Advanced XL (Qiagen). The DNA was then concentrated and purified using the Qiamp kit (Qiagen). The yield and the concentration was measured by the Quant-it Picogreen kit (Invitrogen) on the Genios Tecan fluorometer at $50 \mathrm{ng} / \mu \mathrm{l}$.

\section{Genome sequencing and assembly}

Genomic DNA of $M$. gorillae was sequenced on the MiSeq Technology (Illumina Inc, San Diego, CA, USA) with the 2 applications: paired end and mate paired. The gDNA was barcoded in order to be mixed with 11 others projects with the Nextera Mate Pair sample prep kit (Illumina) and with 17 others projects with the Nextera XT DNA sample prep kit (Illumina).

gDNA was quantified by a Qubit assay with the high sensitivity kit (Life technologies, Carlsbad, CA, USA) to $46.7 \mathrm{ng} / \mu \mathrm{lTo}$ prepare the paired end library, dilution was performed to require $1 \mathrm{ng}$ of each genome as input. The " tagmentation " step fragmented and tagged the DNA. Then limited cycle PCR amplification (12 cycles) completed the tag adapters and introduced dual-index barcodes. After purification on AMPure XP beads (Beckman Coulter Inc, Fullerton, CA, USA), the libraries were then normalized on specific beads according to the Nextera XT protocol (Illumina). Normalized libraries were pooled for sequencing on the MiSeq. The pooled single strand library was loaded onto the reagent cartridge and then onto the instrument along with the flow cell. Automated cluster generation and 
paired end sequencing with dual index reads were performed in a single $39-\mathrm{h}$ run in 2x250-bp.

Total information of $7.6 \mathrm{~Gb}$ was obtained from a $931 \mathrm{~K} /$ $\mathrm{mm}^{2}$ cluster density with a cluster passing quality control filters of $82.8 \%$ (17,658,000 clusters). Within this run, the index representation for $M$. gorillae was determined to $5.11 \%$. The 732,922 paired end reads were trimmed and filtered by Trimmomatic tool using the recommended parameters for Illumina sequence data [19].

Two mate pair libraries were prepared with 1 and $1.5 \mu \mathrm{g}$ of genomic DNA using the Nextera mate pair Illumina guide. The genomic DNA sample was simultaneously fragmented and tagged with a mate pair junction adapter. The pattern of the fragmentation was validated on an Agilent 2100 BioAnalyzer (Agilent Technologies Inc, Santa Clara, CA, USA) with a DNA 7500 labchip. The DNA fragments ranged from $1 \mathrm{~kb}$ to $11 \mathrm{~kb}$ in size with the majority of fragments at 8.8 and $9.4 \mathrm{~kb}$ of size. No size selection was performed and $45 \mathrm{ng}$ for the $1^{\text {st }}$ library and $600 \mathrm{ng}$ for the second library of tagmented fragments were circularized. The circularized DNA was mechanically sheared to small fragments with the majority at 400 and 380 bp on the Covaris device S2 in microtubes (Covaris, Woburn, MA, USA). The library profile was visualized on a High Sensitivity Bioanalyzer LabChip (Agilent Technologies Inc, Santa Clara, CA, USA) and the final concentration library was measured at 0.65 and $0.59 \mathrm{nmol} / \mathrm{l}$ respectively. The libraries were normalized at $2 \mathrm{nM}$ and pooled. After a denaturation step and dilution at $15 \mathrm{pM}$, the pool of libraries was loaded onto the reagent cartridge and then onto the instrument along with the flow cell. Automated cluster generation and sequencing run were performed in a single 39 -h run in a 2x251-bp. The first libray was loaded three times on a flowcell and the second once. Within these runs, the index representation for $M$. gorillae was determined as an average at $3.51 \%$. The $1,881,286$ paired reads were filtered according to the read qualities. The global paired end and mate pair libraries lead to 2,614,208 paired reads which were trimmed by Trimmomatic [19] then assembled by Spades software using the recommended options "-careful" and "-k 127" to fix the kmer size to 127 [20]. The final assembly identified 14 scaffolds generating a genome size of $3.69 \mathrm{Mb}$ which corresponds to genome coverage of $213 \mathrm{X}$.

\section{Genome annotation}

Open Reading Frames (ORFs) were predicted using Prodigal [21] with default parameters but the predicted ORFs were excluded if they spanned a sequencing gap region. The predicted bacterial protein sequences were searched against the GenBank database [22] and the Clusters of Orthologous Groups (COG) databases using BLASTP. The tRNAScanSE tool [23] was used to find
tRNA genes, whereas ribosomal RNAs were found using RNAmmer [24] and BLASTn against the GenBank database. Lipoprotein signal peptides and the number of transmembrane helices were predicted using SignalP [25] and TMHMM [26] respectively. ORFans were identified if their BLASTP E-value was lower than 1e-03 for alignment length greater than 80 amino acids. If alignment lengths were smaller than 80 amino acids, we used an E-value of 1e-05. Such parameter thresholds have already been used in previous works to define ORFans. Artemis [27] was used for data management and DNA Plotter [28] for visualization of genomic features. The Mauve alignment tool (version 2.3.1) was used for multiple genomic sequence alignment [29]. To estimate the mean level of nucleotide sequence similarity at the genome level between $M$. gorillae sp. nov. strain G3T and other members of the genus Microbacterium, we used the MAGI home-made software to calculate the average genomic identity of gene sequences (AGIOS) among compared genomes [30]. Briefly, this software combines the Proteinortho software [31] for detecting orthologous proteins in pairwise genomic comparisons, then retrieves the corresponding genes and determines the mean percentage of nucleotide sequence identity among orthologous ORFs using the Needleman-Wunsch global alignment algorithm. Finally, we used Genome-toGenome Distance Calculator (GGDC) web server available at (http://ggdc.dsmz.de) to estimate of the overall similarity among the compared genomes and to replace the wet-lab DNA-DNA hybridization (DDH) by a digital $\mathrm{DDH}(\mathrm{dDDH})[32,33]$. GGDC 2.0 BLAST+ was chosen as alignment method and the recommended formula 2 was taken into account to interpret the results.

\section{Genome properties}

The genome of M. gorillae strain $\mathrm{G}^{\mathrm{T}}$ is $3,692,770 \mathrm{bp}$ long with a $69.3 \% \mathrm{G}+\mathrm{C}$ content (Table 3, Fig. 3). Of the 3,566 predicted genes, 3,505 were protein-coding genes and 61 were RNA genes, including 4 complete rRNA operons (Additional file 4). A total of 2,412 genes $(68.82 \%)$ were assigned a putative function. A total of $6.33 \%$ were identified as Pseudo-genes. The remaining genes were annotated as hypothetical proteins. The properties and the statistics of the genome are summarized in Table 3. The distribution of genes into COGs functional categories is presented in Table 4 and Additional file 4.

\section{Insights from the genome sequence}

Here, we compared the genome sequences of $M$. gorillae strain G3 ${ }^{\mathrm{T}}$ (CDAR00000000) with those of Microbacterium barkeri strain 2011-R4 (AKVP00000000), Microbacterium maritypicum strain MF109 (ATAO00000000), Microbacterium indicum strain DSM 19969 (AULR00000000), 
Table 3 Nucleotide content and gene count levels of the genome

\begin{tabular}{lll}
\hline Attribute & Value & $\%$ of total $^{a}$ \\
\hline Genome size (bp) & $3,692,770$ & 100 \\
DNA coding (bp) & $3,396,745$ & 92 \\
DNA G + C (bp) & $2,558,287$ & 69.3 \\
DNA scaffolds & 14 & \\
Total genes & 3,566 & 100 \\
Protein coding genes & 3,505 & 98.3 \\
RNA genes & 61 & 1.71 \\
Pseudo genes & 226 & 6.33 \\
Genes in internal clusters & ND & ND \\
Genes with function prediction & 2,412 & 68.8 \\
Genes assigned to COGs & 2,202 & 62.8 \\
Genes with Pfam domains & 0 & 0 \\
Genes with signals peptides & 365 & 10.4 \\
Genes with transmembrane helices & 843 & 24.1 \\
CRISPR repeats & 0 & 0 \\
\hline
\end{tabular}

${ }^{a}$ The total is based on either the size of the genome in base pairs or the total number of protein coding genes in the annotated genome ND: Not determined
Microbacterium laevaniformans strain OR221 (AJGR00 000000), Microbacterium luticocti strain DSM 19459 (AULS00000000), Microbacterium paraoxydans strain 77MFTsu3.2 (AQYI00000000), Microbacterium testaceum strain StLB037 (AP012052) and Microbacterium yannicii strain PS01 (CAJF00000000). The draft genome of $M$. gorillae has a larger size than those of $M$. indicum, $M$. luticocti, M. laevaniformans, $M$. paraoxydans and M. barkeri, (3.69 vs 2.81, 3.11, 3.43, 3.48 and 3.64 Mb respectively) but is smaller than those of $M$. maritypicum, M. testaceum and M. yannicii (3.69 vs 4.0, 3.98 and $3.95 \mathrm{Mb}$ respectively). The $\mathrm{G}+\mathrm{C}$ content of $M$. gorillae is higher than those of $M$. laevaniformans and M. maritypicum (69.3 vs 68.0 and $68.2 \%$ respectively) but lower than those of $M$. indicum, M. luticocti, M. testaceum, M. yannicii, M. paraoxydans and $M$. barkeri $(69.3$ vs $71.4,70.7,70.3,69.5,69.5,69.2 \%$, respectively). The gene content of $M$. gorillae is lower than those of $M$. maritypicum and $M$. testaceum, (3,505 vs 3,856 and 3,676 genes respectively) but higher than those of, $M$. paraoxydens, M. yannicii, $M$. laevaniformans, $M$. barkeri, M. luticocti and M. indicum (3,312, 3,279. 3,249, $3,099,2,355$, 2,183 genes respectively) (Table 5). However the distribution of genes into COG categories was similar

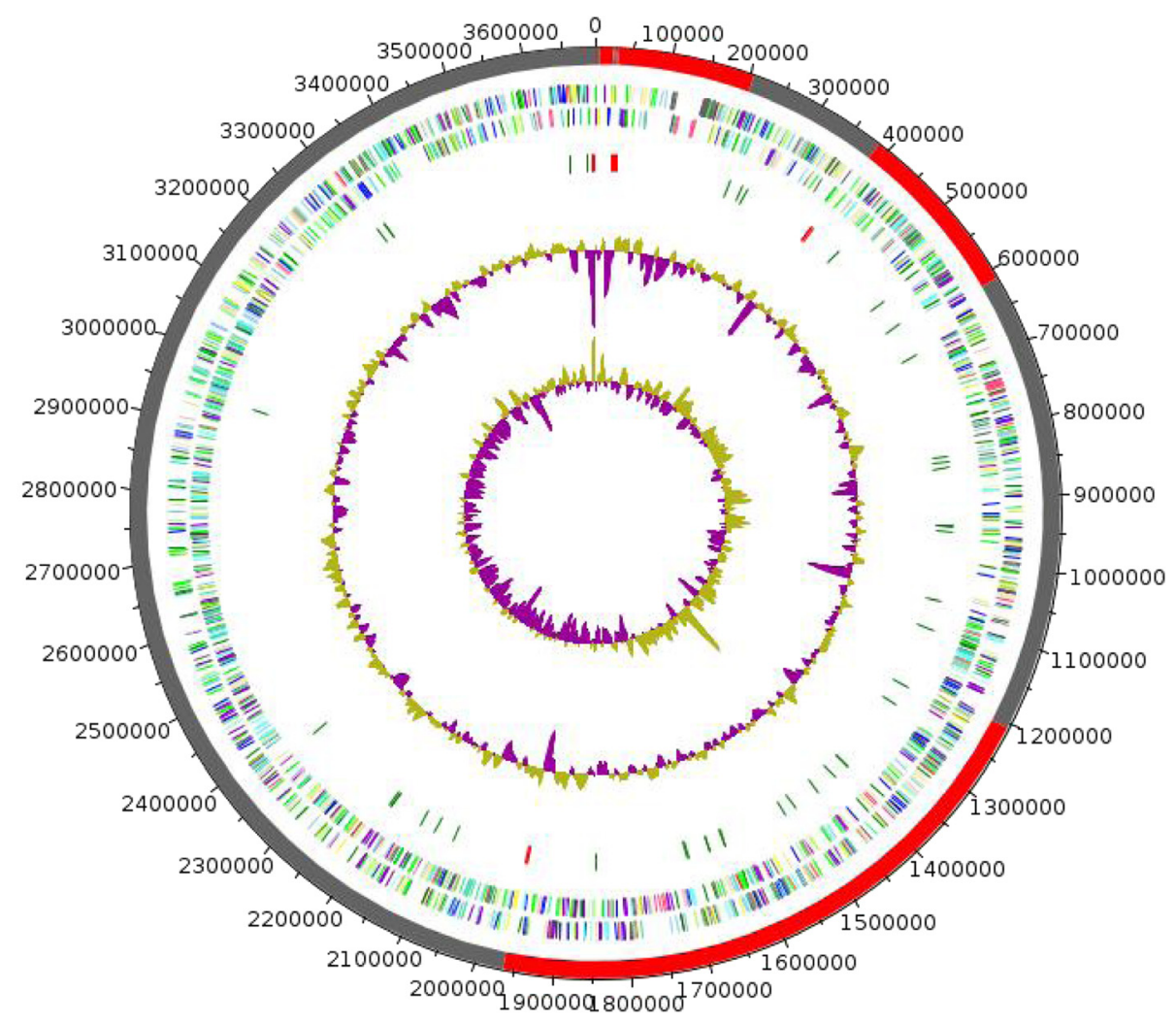

Fig. 3 Graphical circular map of the Microbacterium gorillae strain $G 3^{\top}$ chromosome. The outer two circles show open reading frames oriented in the forward (colored by COG categories) and reverse (colored by COG categories) directions, respectively. The third circle shows the RNA genes (tRNAs green, rRNAs red). The fourth circle shows the $\mathrm{G}+\mathrm{C} \%$ content plot. The inner-most circle shows GC skew, purple indicating negative values whereas olive for positive values 
Table 4 Number of genes associated with the 25 general COG functional categories

\begin{tabular}{|c|c|c|c|}
\hline Code & Value & $\%$ of total ${ }^{a}$ & Description \\
\hline J & 149 & 4.25 & Translation \\
\hline A & 1 & 0.03 & RNA processing and modification \\
\hline K & 269 & 7.67 & Transcription \\
\hline L & 109 & 3.11 & Replication, recombination and repair \\
\hline B & 0 & 0.00 & Chromatin structure and dynamics \\
\hline D & 16 & 0.46 & Cell cycle control, mitosis and meiosis \\
\hline Y & 0 & 0.00 & Nuclear structure \\
\hline V & 41 & 1.17 & Defense mechanisms \\
\hline T & 75 & 2.14 & Signal transduction mechanisms \\
\hline M & 82 & 2.34 & Cell wall/membrane biogenesis \\
\hline N & 1 & 0.03 & Cell motility \\
\hline Z & 0 & 0.00 & Cytoskeleton \\
\hline W & 0 & 0.00 & Extracellular structures \\
\hline$U$ & 24 & 0.68 & Intracellular trafficking and secretion \\
\hline $\mathrm{O}$ & 66 & 1.88 & Posttranslational modification, protein turnover, chaperones \\
\hline C & 150 & 4.28 & Energy production and conversion \\
\hline G & 257 & 7.33 & Carbohydrate transport and metabolism \\
\hline E & 325 & 9.27 & Amino acid transport and metabolism \\
\hline $\mathrm{F}$ & 69 & 1.97 & Nucleotide transport and metabolism \\
\hline $\mathrm{H}$ & 83 & 2.37 & Coenzyme transport and metabolism \\
\hline । & 151 & 4.31 & Lipid transport and metabolism \\
\hline P & 184 & 5.25 & Inorganic ion transport and metabolism \\
\hline Q & 95 & 2.71 & Secondary metabolites biosynthesis, transport and catabolism \\
\hline R & 410 & 11.70 & General function prediction only \\
\hline S & 145 & 4.14 & Function unknown \\
\hline- & 1303 & 37.17 & Not in COGs \\
\hline
\end{tabular}

${ }^{a}$ The total is based on the total number of protein coding genes in the annotated genome

in all compared genomes (Additional file 5: Figure S3). In yannicii respectively (Table 5). Among compared genomes addition, M. gorillae shares 1,593, 1,658, 1,269, 1,396, 1,390, 1,416, 1,498 and 1,497 orthologous genes with $M$. barkeri, $M$. maritypicum, $M$. indicum, M. laevaniformans, except $M$. gorillae, AGIOS values range from $75.51 \%$ between $M$. indicum and M. maritypicum to $85.33 \%$ between $M$. maritypicum and M. barkeri . When M. gorilM. luticocti, M. paraoxydans, $M$. testaceum and $M$. lae was compared to other species, AGIOS values range

Table 5 Genomic comparison of M. gorillae sp. nov., strain G3 ${ }^{\top}$ with other Microbacterium species.

\begin{tabular}{llllllllll}
\hline Species & M. gorillae & M. barkeri & M. maritypicum & M. indicum & M. laevaniformans & M. luticocti & M. paraoxydans & M. testaceum & M. yannicii \\
\hline M. gorillae & $\mathbf{3 , 5 0 5}$ & 1,593 & 1,658 & 1,269 & 1,396 & 1,390 & 1,416 & 1,498 & 1,497 \\
M. barkeri & 75.91 & $\mathbf{3 , 0 9 9}$ & 2,111 & 1,390 & 1,511 & 1,461 & 1,595 & 1,685 & 1,684 \\
M. maritypicum & 75.22 & 85.33 & $\mathbf{3 , 8 5 6}$ & 1,429 & 1,581 & 1,549 & 1,634 & 1,755 & 1,734 \\
M. indicum & 75.39 & 76.16 & 75.51 & $\mathbf{2 , 1 8 3}$ & 1,296 & $\mathbf{1 , 1 9 1}$ & 1,324 & 1446 & 1,349 \\
M. laevaniformans & 75.80 & 76.59 & 76.07 & 76.05 & $\mathbf{3 , 2 4 9}$ & 1414 & 1,602 & 1,638 & 1,580 \\
M. luticocti & 76.41 & 76.99 & 76.50 & 76.34 & 77.94 & $\mathbf{2 , 3 5 5}$ & 1,395 & 1,433 & 1,512 \\
M. paraoxydans & 75.66 & 76.36 & 75.90 & 76.43 & 78.49 & 77.34 & $\mathbf{3 , 3 1 2}$ & 1,710 & 1,632 \\
M. testaceum & 75.64 & 76.48 & 75.84 & 76.30 & 77.64 & 77.64 & 77.52 & $\mathbf{3 , 6 7 6}$ & 1,723 \\
M. yannicii & 75.85 & 76.89 & 76.34 & 76.53 & 78.06 & 78.60 & 77.82 & $\mathbf{7 8 . 1 0}$ & $\mathbf{3 , 2 7 9}$ \\
\hline
\end{tabular}

The numbers of orthologous proteins shared between genomes (upper right triangle), average percentage similarity of nucleotides corresponding to orthologous protein shared between genomes (lower left triangle) and numbers of proteins per genome (bold) 
from $75.22 \%$ with $M$. maritypicum to $76.41 \%$ with $M$. luticocti (Table 5). dDDH estimation of the strain $\mathrm{G}^{\mathrm{T}}$ against the compared genomes ranged between 19.70 to 20.50. These values are very low and below the cutoff of $70 \%$, thus confirming again the new species status of the strain $\mathrm{G} 3^{\mathrm{T}}$.

\section{Conclusions}

On the basis of phenotypic characteristics, phylogenetic position, genomic analyses (taxonogenomics) and GGDC results, we formally propose the creation of Microbacterium gorillae sp. nov. that contains the strain $\mathrm{G}^{\mathrm{T}}$. This strain has been isolated from a gorilla stool sample collected from Cameroon.

\section{Taxonomic and nomenclatural proposals Description of Microbacterium gorillae sp. nov.}

Microbacterium gorillae (go.ril'lae. NL neut. gen gorilla, pertaining to a gorilla from which the stool sample was obtained).

Cells stain Gram-positive, are small rod, nonendospore-forming, non-motile and have a diameter of $0.5 \mu \mathrm{m}$ and a length of $1 \mu \mathrm{m}$. Colonies are gray and $2 \mathrm{~mm}$ in diameter on blood-enriched Columbia agar. Growth occurs between 25 and $37{ }^{\circ} \mathrm{C}$, with optimal growth observed at $25^{\circ} \mathrm{C}$.

Strain $\mathrm{G} 3^{\mathrm{T}}$ exhibited catalase activity but not oxidase activity. Strain produces acid from esculin, D-cellobiose, Dmaltose, D-lactose, D-mannose, D-mannitol, D-saccharose, D-trehalose and gentiobiose but not from glycerol, erythritol, D-arabinose, L-arabinose, D-ribose, D-xylose, L-xylose, D-adonitol, methyl- $\alpha \mathrm{D}$-xylopyranoside, D-galactose, Dglucose, L-fructose, L-sorbose, L-rhamnose, dulcitol, inositol, D-sorbitol, methyl- $\alpha \mathrm{D}$-mannopyranoside, Methyl$\alpha \mathrm{D}$-glucopyranoside, xylitol, D-tagatose, D-turanose, Dlyxose, D-fucose, L-fucose, D-arabitol, L-arabitol, potassium gluconate, potassium 2-cetogluconate, potassium 5cetogluconate, D-melezitose, D-raffinose, Glycogen, $\mathrm{N}$-acetylglucosamin, amygdalin, arbutin, salicin and hydrolysis of starch.

Positive enzyme activities were observed for esterase (C4), esterase lipase (C8), leucine aramidase, phosphatase acid, naphtol-AS-BI-phosphohydrolase, $\alpha$-mannosidase, $\alpha$ - glucosidase and $\mathrm{N}$-acetyl- $\beta$-glucosaminidase. Negative results for lipase (C14), phosphatase alcalin, valine arylamidase, cystine arylamidase, trypsin, $\alpha$-chymotrypsin, $\alpha$-galactosidase, $\beta$ - galactosidase, $\beta$-glucosidase, $\beta$ glucuronidase, $\beta$-glucosidase, and $\alpha$-fucosidase.

M. gorillae is susceptible to amoxicillin, erythromycin, doxycyclin, rifampicin, vancomycin, amoxicillin-clavulanic acid, trimethoprim-sulfamethoxazole and imipenem but resistant to ciprofloxacin and gentamycin.

The $\mathrm{G}+\mathrm{C}$ content of the genome is $69.3 \%$. The $16 \mathrm{~S}$ rRNA and genome sequences are deposited in GenBank under accession numbers JX650056 and CDAR00000000, respectively. The type strain $\mathrm{G}^{\mathrm{T}}{ }^{\mathrm{T}}(=$ CSUR P207 $=$ DSM 26203) was isolated from the fecal sample of a western lowland gorilla from Cameroon.

\section{Additional files}

\begin{abstract}
Additional file 1: Table S1. Differential phenotypic characteristics between Microbacterium gorillae sp. nov. strain $\mathrm{G} 3^{\top}$ and others Microbacterium strains. (DOCX $14 \mathrm{~kb}$ )
\end{abstract}

Additional file 2: Figure S1. Reference mass spectrum from M. gorillae strain $\mathrm{G}^{\top}$. Spectra from 12 individual colonies were compared and a reference spectrum was generated. (PPTX $44 \mathrm{~kb}$ )

Additional file 3: Figure S2. Gel view comparing Microbacterium gorillae strain G3 ${ }^{\top}$ spectra with other members of the genus Microbacterium. The gel view displays the raw spectra of all loaded spectrum files arranged in a pseudo-gel like look. The $x$-axis records the $\mathrm{m} / \mathrm{z}$ value. The left $\mathrm{y}$-axis displays the running spectrum number originating from subsequent spectra loading. The peak intensity is expressed by a gray-scale scheme code. The color bar and the right $y$-axis indicate the relation between the color a peak is displayed with and the peak intensity in arbitrary units. Displayed species are indicated on the right. (PPTX $76 \mathrm{~kb}$ )

Additional file 4: Folder S1. Annotation results. (RAR $1566 \mathrm{~kb}$ ) Additional file 5: Figure S3. Distribution of functional classes of predicted genes of $M$. gorillae strain $\mathrm{G} 3^{\top}$ with 8 members of Microbacterium genus. (PPTX $63 \mathrm{~kb}$ )

\begin{abstract}
Abbreviations
CSUR: Collection de souches de I'Unité des Rickettsies; URMITE: Unité de Recherche sur les Maladies Infectieuses et Tropicales Emergentes; DSM: Deutsche Sammlung von Mikroorganismen; MALDI-TOF MS: Matrixassisted laser-desorption/ionization time-of-flight mass spectrometry; TE buffer: Tris-EDTA buffer; GGDC: Genome-to-Genome Distance Calculator; dDDH: digital DNA-DNA hybridization.
\end{abstract}

Competing interests

The authors declare that they have no competing interests.

Authors' contributions

$\mathrm{LH}$ wrote the manuscript and analyzed the data. MBK performed laboratory experiments and helped to draft the manuscript. CM performed the sequencing and helped to draft the manuscript. JR and AL performed bioinformatics analysis and helped to draft the manuscript. DR, PF, JMR and FB conceived the study, participated in its design and coordination and helped to draft the manuscript. All authors read and approved the final manuscript.

\section{Acknowledgements}

Fadi Bittar was supported by a Chair of Excellence IRD provided by the Institut de Recherche pour le Développement / Méditerranée-Infection foundation. Mamadou Bhoye Keita was funded by the Méditerranée-Infection foundation. The authors thank Xegen company for automating the genome annotation process

\section{Author details}

${ }^{1}$ Unité de recherche sur les maladies infectieuses et tropicales émergentes (URMITE), UM63, CNRS7278, IRD 198, Inserm 1095, IHU Méditerranée Infection, Faculté de Médecine et de Pharmacie, Aix-Marseille Université, Marseille, France. ${ }^{2}$ King Fahad Medical Research Center, King Abdul Aziz University, Jeddah, Saudi Arabia.

Received: 4 June 2015 Accepted: 8 April 2016

Published online: 14 April 2016 


\section{References}

1. Bittar F, Keita MB, Lagier JC, Peeters M, Delaporte E, Raoult D. Gorilla gorilla gorilla gut: a potential reservoir of pathogenic bacteria as revealed using culturomics and molecular tools. Sci Rep. 2014;4:7174.

2. Skerman VBD, McGowan V, Sneath PHA. Approved Lists of Bacterial Names. Int J Syst Bacteriol. 1980:30:225-420.

3. Abstract for the genus Microbacterium. NamesforLife, LLC. Retrieved June 26, 2015. (doi:10.1601/tx.6034).

4. Gneiding K, Frodl R, Funke G. Identities of Microbacterium spp. Encountered in Human Clinical Specimens. J Clin Microbiol. 2008;46:3646.

5. Anand S, Bala K, Saxena A, Schumann P, Lal R. Microbacterium amylolyticum sp. nov., isolated from soil from an industrial waste site. Stand Int J Syst Evol Microbiol. 2012:62:2114-20.

6. Bakir MA, Kudo T, Benno Y. Microbacterium hatanonis sp. nov., isolated as a contaminant of hairspray. Int J Syst Evol Microbiol. 2008;58(Pt 3):654-8.

7. Alves A, Riesco R, Correia A, Trujillo ME. Microbacterium proteolyticum sp. nov. isolated from roots of Halimione portulacoides. Int J Syst Evol Microbiol. 2015;65(Pt 6):1794-8

8. Sentausa E, Fournier PE. Advantages and limitations of genomics in prokaryotic taxonomy. Clin Microbiol Infect. 2013;19(9):790-5.

9. Meier-Kolthoff JP, Göker M, Spröer C, Klenk HP. When should a DDH experiment be mandatory in microbial taxonomy? Arch Microbiol. 2013;6:413-8.

10. Zhang $Y$, Ren H, Zhang G. Microbacterium hydrothermale sp. nov., an actinobacterium isolated from hydrothermal sediment. Int J Syst Evol Microbiol. 2014;64:3508-12

11. Shivaji S, Bhadra B, Rao RS, Chaturvedi P, Pindi PK, Raghukumar C. Microbacterium indicum sp. nov., isolated from a deep-sea sediment sample from the Chagos Trench, Indian Ocean. Int J Syst Evol Microbiol. 2007;57: 1819-22.

12. Vaz-Moreira I, Lopes AR, Falsen E, Schumann P, Nunes OC, Manaia CM. Microbacterium luticocti sp. nov., isolated from sewage sludge compost. Int J Syst Evol Microbiol. 2008;58:1700-4.

13. Laffineur K, Avesani V, Cornu G, Charlier J, Janssens M, Wauters G, et al. Bacteremia due to a novel Microbacterium species in a patient with leukemia and description of Microbacterium paraoxydans sp. nov. J Clin Microbiol. 2003:41(5):2242-6.

14. Schippers A, Bosecker K, Sproer C, Schumann P. Microbacterium oleivorans sp. nov. and Microbacterium hydrocarbonoxydans sp. nov., novel crude-oil-degrading Gram-positive bacteria. Int J Syst Evol Microbiol. 2005;55(Pt 2):655-60.

15. Sharma P, Diene SM, Thibeaut S, Bittar F, Roux V, Gomez C, et al. Phenotypic and genotypic properties of Microbacterium yannicii, a recently described multidrug resistant bacterium isolated from a lung transplanted patient with cystic fibrosis in France. BMC Microbiol. 2013;13:97.

16. Takeuchi M, Hatano K. Proposal of six new species in the genus Microbacterium and transfer of "Flavobacterium marinotypicum" ZoBell and Upham to the genus Microbacterium as Microbacterium maritypicum comb. nov. Int J Syst Bacteriol. 1998:48 Pt 3:973-82

17. Seng $P$, Drancourt $M$, Gouriet $F$, et al. Ongoing revolution in bacteriology: routine identification of bacteria by matrix-assisted laser desorption ionization time-of-flight mass spectrometry. Clin Infect Dis. 2009;49:543-51.

18. Field D, Garrity G, Gray T, et al. The minimum information about a genome sequence (MIGS) specification. Nat Biotechnol. 2008;26:541-7.

19. Bolger AM, Lohse $M$, Usadel B. Trimmomatic: a flexible trimmer for Illumina sequence data. Bioinformatics. 2014;30:2114-20.

20. Bankevich A, Nurk S, Antipov D, Gurevich AA, Dvorkin M, Kulikov AS, et al. SPAdes: a new genome assembly algorithm and its applications to singlecell sequencing. J Comput Biol. 2012;19:455-77.

21. Prodigal. [http://prodigal.ornl.gov].

22. GenBank database. http://www.ncbi.n/m.nih.gov/genbank.

23. Lowe TM, Eddy SR. tRNAscan-SE: a program for improved detection of transfer RNA genes in genomic sequence. Nucleic Acids Res. 1997;25:955-64.

24. Lagesen $K$, Hallin P, Rodland EA, Staerfeldt HH, Rognes T, Ussery DW. RNAmmer: consistent and rapid annotation of ribosomal RNA genes. Nucleic Acids Res. 2007:35:3100-8.

25. Bendtsen JD, Nielsen H, von Heijne G, Brunak S. Improved prediction of signal peptides: SignalP 3.0. J Mol Biol. 2004;340:783-95.

26. Krogh A, Larsson B, von Heijne G, Sonnhammer EL. Predicting transmembrane protein topology with a hidden Markov model: application to complete genomes. J Mol Biol. 2001;305:567-80.

27. Rutherford K, Parkhill J, Crook J, Horsnell T, Rice P, Rajandream MA, Barrell B. Artemis: sequence visualization and annotation. Bioinformatics. 2000;16:944-5.
28. Carver T, Thomson N, Bleasby A, Berriman M, Parkhill J. DNAPlotter: circular and linear interactive genome visualization. Bioinformatics. 2009;25:119-20.

29. Darling AC, Mau B, Blattner FR, Perna NT. Mauve: multiple alignment of conserved genomic sequence with rearrangements. Genome Res. 2004; 14:1394-403.

30. Ramasamy D, Mishra AK, Lagier JC, et al. A polyphasic strategy incorporating genomic data for the taxonomic description of novel bacterial species. Int J Syst Evol Microbiol. 2014;64:384-91.

31. Lechner M, Findeiss S, Steiner L, Marz M, Stadler PF, Prohaska SJ. Proteinortho: detection of (co-)orthologs in large-scale analysis. BMC Bioinformatics. 2011:12:124.

32. Auch AF, von Jan M, Klenk HP, Göker M. Digital DNA-DNA hybridization for microbial species delineation by means of genome-to-genome sequence comparison. Stand Genomic Sci. 2010;2:117-34.

33. Meier-Kolthoff JP, Auch AF, Klenk HP, Göker M. Genome sequence-based species delimitation with confidence intervals and improved distance functions. BMC Bioinformatics. 2013;14:60.

34. Woese CR, Kandler O, Wheelis ML. Towards a natural system of organisms: proposal for the domains Archae, Bacteria, and Eukarya. Proc Natl Acad Sci U S A. 1990:87:4576-9.

35. Stackebrandt E, Rainey FA, Ward-Rainey NL. Proposal for a new hierarchic classification system, Actinobacteria classis nov. Int I Syst Bacteriol. 1997:47:479-91.

36. Validation List no. 53 in IJSEM. Validation of the Publication of New Names and New Combinations Previously Effectively Published Outside the IJSB. Int J Syst Evol Microbiol. 1995;25:418-9.

37. Ashburner M, Ball CA, Blake JA, Botstein D, Butler $\mathrm{H}$, Cherry JM, et al. Gene ontology: tool for the unification of biology. The Gene Ontology Consortium Nat Genet. 2000;25:25-9.

38. Castresana J. Selection of conserved blocks from multiple alignments for their use in phylogenetic analysis. Mol Biol Evol. 2000;17:540-52.

39. Stamatakis A. RAxML-VI-HPC: maximum likelihood-based phylogenetic analyses with thousands of taxa and mixed models. Bioinformatics. 2006:22:2688-90.

\section{Submit your next manuscript to BioMed Central and we will help you at every step:}

- We accept pre-submission inquiries

- Our selector tool helps you to find the most relevant journal

- We provide round the clock customer support

- Convenient online submission

- Thorough peer review

- Inclusion in PubMed and all major indexing services

- Maximum visibility for your research

Submit your manuscript at www.biomedcentral.com/submit
) Biomed Central 